\title{
A pilot study on identification of perinatal depressive symptoms in mother-child health clinics: Community nurses can make a difference
}

\author{
Saralee Glasser ${ }^{1}$, Dorit Appel ${ }^{2}$, Hannah Meiraz ${ }^{2}$, Giora Kaplan ${ }^{1}$ \\ 1. Gertner Institute for Epidemiology and Health Policy Research, Sheba Medical Center, Ramat Gan, Israel. 2. Public \\ Health Services, Ministry of Health, Jerusalem, Israel
}

Correspondence: Saralee Glasser. Address: Gertner Institute for Epidemiology \& Health Policy Research, Sheba Medical Center, Tel Hashomer, Israel, 52621. Email: saraleeg@gertner.health.gov.il.

Received: November 6, 2012

Accepted: January 16, $2013 \quad$ Online Published: April 15, 2013

DOI : $10.5430 /$ jnep.v3n11p1

URL: http://dx.doi.org/10.5430/jnep.v3n11p1

\begin{abstract}
Postpartum depression is a common and troubling phenomenon calling for identification, diagnosis and treatment. Community health nurses caring for pregnant and postpartum women can contribute to this process. The aim of this study was to evaluate a pilot program for identification of women suffering from, or at risk for postpartum depression. Screening was done with the Edinburgh Postpartum Depression Scale, and nurses provided supportive intervention where indicated. Analysis of a sub-group indicated that nurses' intervention during pregnancy may contribute to lower rates of depressive symptoms postpartum. Screening and supportive intervention was feasible and acceptable to mothers and nurses. The Israel Ministry of Health has recommended expanding this program to all Mother-Child-Health clinics.
\end{abstract}

\section{Key words}

Postpartum depression, Maternal-child health care, Community nurse, Screening

\section{I ntroduction}

In recent years there has been growing awareness of women's health issues in general, and mental distress during pregnancy and postpartum, in particular. Although the birth of a baby is generally a happy occasion, it can also be a stressful one. Mothers suffer from various emotional upheavals following childbirth: from mild, non-pathological state of 'postpartum blues' lasting a few days, and noted in 50\%-80\% of deliveries, to depressive episodes lasting weeks or months, and to psychotic episodes, noted in $0.1 \%-0.2 \%$ of deliveries ${ }^{[1,2]}$. Of these conditions, postpartum depression (PPD) is of particular concern to community health workers. The symptom profile is similar to depression occurring at other times in life, with the following prevailing symptoms: depressed mood, anhedonia, sleep disorders, appetite disorders, extreme fatigue, agitation, loss of concentration, excessive guilt, thoughts of self-inflicted harm, and may include rejection of the baby, thoughts of hurting the baby, stress, anxiety, and somatic features ${ }^{[3]}$.

The prevalence of PPD, although varying according to definition and methodology, is estimated to be $10 \%-20 \%{ }^{[4,5]}$, with findings in this range reported from various studies in Israel ${ }^{[6,7]}$ and around the world ${ }^{[8-12]}$, making depression one of the 
most prevalent complications of childbirth ${ }^{[4,13,14]}$. Both short- and long-term consequences of PPD are apparent for the woman herself ${ }^{[15-18]}$, and also for her infant/child ${ }^{[19-23]}$, her partner ${ }^{[24]}$, and other children in the family ${ }^{[25]}$.

Despite the prevalence of the phenomenon and the frequency of contacts between women and health personnel during pregnancy and postpartum, most cases are not identified, diagnosed or treated ${ }^{[26,27]}$. Thus, the mother's distress, as well as the potentially negative influences on the physical, emotional, and cognitive development of the baby, and on the entire family, often goes unnoticed and unattended.

The prevalence, severity and consequences of PPD make early identification and intervention a high-priority case for action in the public health sector's community services ${ }^{[28]}$. Programs in this framework have been reported in various countries $^{[29-31]}$. In light of the findings of a prospective study of PPD in an Israeli cohort ${ }^{[6,7]}$, the Public Health Services of the Israel Ministry of Health decided to develop a program for early and systematic identification of women with depressive symptoms during pregnancy and the postpartum period. Implementation was to be done at the Mother and Child Health Clinics (MCHC), which are community health centers, for several reasons: (1) the service is universal, with a broad network throughout the country; (2) 95\% of the families in Israel use the services of the MCHC during and/or after pregnancy ${ }^{[32]}$; (3) it is considered a non-stigmatic framework; and (4) the fact MCHC nurses come in frequent contact with mothers during this pivotal period of their lives provides the opportunity to offer professional assistance and support.

The program aimed at improving the service provided to pregnant and postpartum women by means of early identification and intervention in cases reporting symptoms of depression. It was begun as a pilot project, in order to verify its feasibility and acceptability by both the nurses and the women in their care. The current paper presents a description and evaluation of the program.

\section{Method}

\subsection{Design}

Descriptive study with quantitative and qualitative aspects.

\subsection{Subjects}

Women attending six MCHC's in different parts of the country participated in the pilot project. The research sample included all women attending these clinics during one year who were in the 26th week or more of pregnancy and/or approximately 6-8 weeks postpartum.

\subsection{Variables}

Independent variable: Timing of measurement--during pregnancy or postpartum.

Dependent variable: Depression as defined by score on the Edinburgh Postnatal Depression Scale ${ }^{[33]}$.

\subsection{I nstruments}

Depressive symptoms were assessed using the Edinburgh Postnatal Depression Scale (EPDS), a self-rating questionnaire that reflects the subject's feelings over the past week ${ }^{[33]}$. The EPDS has been translated and validated in many languages and cultures including in the Hebrew version ${ }^{[8,34,35]}$. It has been found sensitive in identifying even mild cases of depression, making it especially relevant for community samples ${ }^{[36,37]}$. It includes 10 items, with scores ranging from 0 -30. A score of $\geq 10$ has been recommended for identifying women at-risk of depression in primary health services, while a score of $\geq 13$ likely reflects moderate to severe depressive symptoms ${ }^{[3,8,38]}$. 
The program was monitored on: (a) forms listing all eligible women attending the clinics during the study period, whether or not they completed the EPDS; (b) forms for recording intervention activities provided by the nurses.

A program evaluation questionnaire was prepared for nurses to complete, with a various aspects of their screening and support activities, rated on a 4-point likert scale with the following options: "to a very great extent," "to a great extent," "somewhat," and "not at all." In addition, the program was assessed qualitatively by means of open questions answered by the nurses in writing at the program's culmination.

\subsection{Procedure}

Program Preparation: Consent and cooperation were obtained from all relevant Ministry of Health departments, including the Public Health Division and Public Health Nursing Services. The Sheba Medical Center Helsinki Committee approved the program. Plans for interface between the Ministry's Public Health and Mental Health services were established to provide professional backing and to treat cases, if necessary. Guidelines were established for nurses' screening and supportive intervention activities. A 12-hour training program was conducted for MCHC nurses in the participating clinics, which included theoretical aspects of PPD, as well as review of all guidelines for the screening and intervention.

Program Implementation: All pregnant women attending participating clinics during the pilot program were offered an explanation of the program by the nurses and asked to participate, once from their 26th week of pregnancy and at approximately 6-8 weeks following delivery. Consenting women were given the EPDS to complete and the nurse then reviewed the questionnaire, calculated the score, and discussed the findings with the woman. If the score was $\geq 10$, if the score for Question 10 was >0 (indicating thoughts of self-harm), or if the woman expressed apparent distress, regardless of the score, supportive intervention was begun according to the guidelines. Participating clinics were accompanied by Mental Health Coordinating Nurses, whose functions included: (1) counseling nurses on issues or questions relating to the program; (2) meeting at the clinic with women who scored $\geq 13$ on the EPDS, and who agreed to such a meeting; and (3) determining the necessity of, and facilitating referral to the regional mental health care clinic.

During the program's implementation, meetings were held between the nurses and the team responsible for the program's planning and implementation (S.G. and D.A) to discuss issues and problems that arose. At the conclusion of the program nurses completed an evaluation questionnaire. A final report of the program's monitoring, evaluation and recommendations was presented to the directors of the Ministry of Health departments involved.

\subsection{Statistical analysis}

Data was entered onto an Excel spreadsheet and converted to a SAS file. Analyses were conducted using the SAS 9.2 Version ${ }^{[35]}$ on UNIX server, and a logic check program was designed for data cleaning. Discrete variables of timing (pregnancy/postpartum) and levels of EPDS score $(0-9 ; 10-12 ; \geq 13)$ were analyzed by chi square analysis, with a $P$ value of 0.05 considered significant. The nurses' evaluation questionnaire results are presented in terms of response percentages, and the qualitative aspects are presented as quotations and representative responses.

\section{Results}

Due to the arbitrary start and finish dates of the program, 136 women participated during pregnancy only, 203 only postpartum, and 56 participated both during pregnancy and postpartum. Thus, a total of 395 mothers participated in the program, completing 451 EPDS forms.

Acceptability: A measure of the program's feasibility was the willingness of attending women to participate, i.e. to complete the EPDS. It was found that rates of refusal varied among the clinics. In three of the clinics, $98.4 \%$ of the potential participants agreed (i.e. 1.6\% refusal rate), as did 90.4\% in the fourth clinic. However in two clinics (both in one 
city), only slightly over half of those offered the EPDS (56.1\%) consented. This refusal rate of $43.9 \%$ was apparently a result of the cultural composition of the population, which will be discussed below.

Rates of Depressive Symptoms: EPDS scores ranged from 0-22 in both periods. Over one-quarter of the pregnant women (26.5\%) and $12.7 \%$ of the postpartum women scored above the cut-off of $\geq 10$, with $13.5 \%$ and $5.4 \%$, respectively, scoring $\geq 13$ (see Table 1). The rates of EPDS $>10$ in the various clinics ranged from $9 \%$ to $20 \%$ in the postpartum period. However, since the program was not planned as a formal research study, and possible selection bias not controlled for, there was no attempt at this time to establish whether there were significant differences in these rates between the clinics.

Table 1. EPDS Scores during Pregnancy and Postpartum

\begin{tabular}{lll}
\hline \multirow{2}{*}{ EPDS Score } & Pregnancy $\mathbf{~}=\mathbf{1 9 2}$ & Postpartum $\mathbf{~}=\mathbf{2 5 9}$ \\
\cline { 2 - 3 } & $\mathbf{n}(\mathbf{\%})$ & $\mathbf{n}(\mathbf{\%})$ \\
\hline$<10$ & $141(73.5)$ & $226(87.3)$ \\
$10-12$ & $25(13.0)$ & $19(7.3)$ \\
$\geq 13$ & $26(13.5)$ & $14(5.4)$ \\
\hline
\end{tabular}

Nurses' Intervention: Eighty-four (21.3\%) of the 395 women who participated in the program received some sort of intervention by the nurse as a result of their responses to the EPDS. According to the nurses' reports, these included 226 distinct activities, including 161 supportive counseling meetings at the clinic, 22 phone calls, 21 consultations with the Mental Health Coordinating Nurse, and ten home visits. Forty-one women were referred to other service providers, with 28 of these being referred to the Mental Health Coordinating Nurse.

Rates of Postpartum Depressive Symptoms by Participation in the Program: As noted, subject participation was determined solely by dates of the pilot project's implementation. Thus, following the onset of the program a woman who came after delivery would have completed the EPDS in the postpartum period only, while a woman who reached the third trimester of her pregnancy towards the end of the program would only have completed the EPDS then and not postpartum. By the end of the project 56 women (clustered in the three clinics with lowest refusal rates) had been able to complete the EPDS both during pregnancy and postpartum. For these women, the opportunity was afforded for intervention to begin, if necessary, during pregnancy. Their postpartum EPDS scores were compared to the rate among women attending those same clinics who completed the EPDS only in the postpartum period, i.e., with no formal intervention. It was found that women in the former group reported lower rates of EPDS $\geq 10$ (8.9\% vs. $19.3 \%$ ), as well as lower rates of EPDS $\geq 13$ (1.8\% vs. 9.6\%) (see Table 2 ). While the differences were not statistically significant ( $P=0.08$ and 0.06 for EPDS $\geq 10$ and $\geq 13$, respectively), the trend is apparent. It should be stressed that there was no selection criteria for these groups other than the date on which the woman attended the clinic having occurred during the study period.

Table 2. Postpartum Depressive Symptoms by Participation in the Program

\begin{tabular}{llll}
\hline Time of Participation & $\mathbf{N}$ & $\mathbf{\%}$ EPDS $>\mathbf{1 0}$ & \% EPDS > 13 \\
\hline Pregnancy \& Postpartum & 56 & 8.9 & 1.8 \\
Postpartum only & 114 & 19.3 & 9.6 \\
$P$ & & 0.08 & 0.06 \\
\hline
\end{tabular}

Nurses’ Evaluation: Twenty-seven nurses responded to the evaluation questionnaire. Twenty-two of them (84.6\% of the respondents; numbers vary slightly due to missing values) considered the 26th week of pregnancy as appropriate timing for EPDS screening (see Figure 1). Although there was no objection to the postpartum screen at 6-8 weeks per se, fewer agreed that it should be conducted in conjunction with the infant's routine visit for inoculation (72\%).

Regarding the screening guidelines, all of the nurses considered them clear, and most (88\%) found them helpful 'to a great/very great extent' in discussing the results with the women. Only four nurses expressed difficulty in presenting the EPDS and its purpose to the women, and three felt the screening posed a problem for themselves 'to a great extent.' 


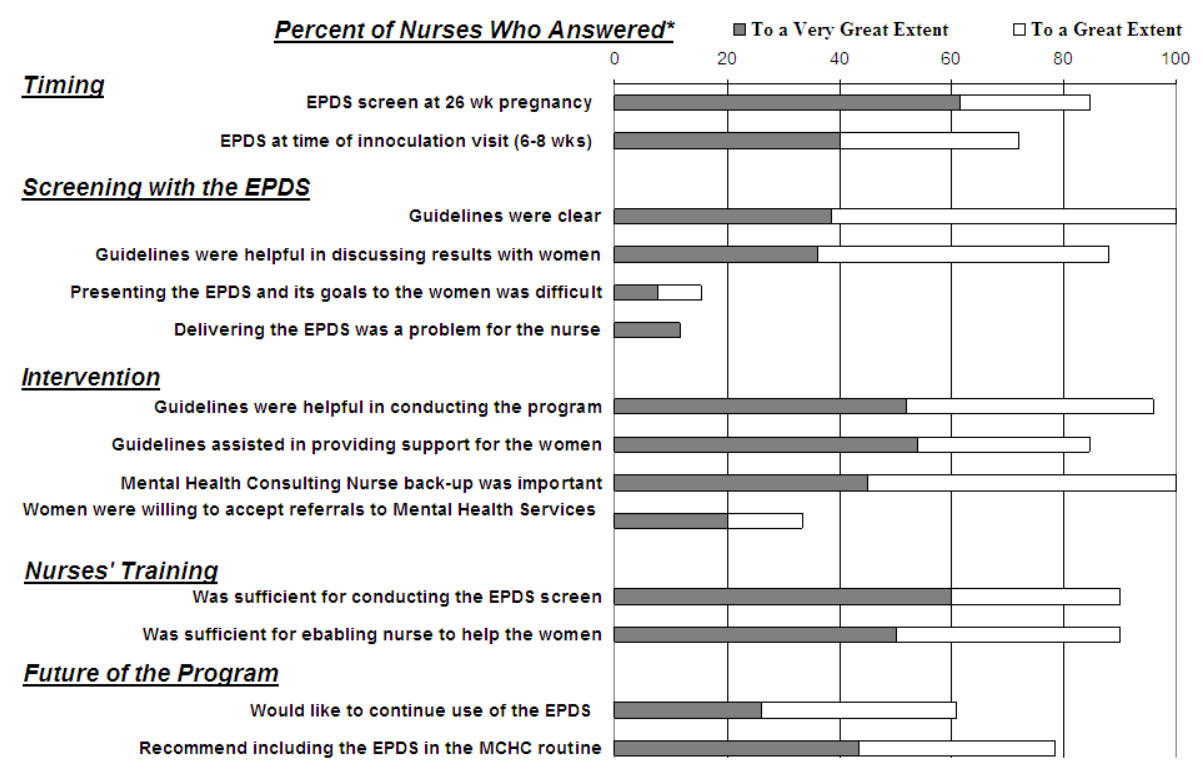

Figure 1. Nurses’ Evaluation of PPD Screeening and Intervention Program

Most nurses considered the intervention guidelines 'very helpful' in conducting the program (96\%) and enabling them to provide support for the women in their care (84.6\%). They all considered the backing of the Mental Health Consulting Nurse to be 'extremely important'. However, when it came to referring women to mental health services if necessary, only one-third reported that women were willing.

Regarding the future of the program, $60.9 \%$ of the respondents stated that they would be interested in continuing it within the context of their work, and over three-quarters (78.3\%) would recommend it becoming part of the routine service provided by nurses in MCHC clinics.

The qualitative aspect of the study was conducted during the summing-up meeting, when the nurses had the opportunity to more fully express their experiences and impressions of the program. Generally, they noted considerable satisfaction with the use of the EPDS, for example:

"It is a great tool"; "The questionnaire allows asking more specific questions than before... and the mothers know to whom they can turn for help."

The nurses described the EPDS as a sensitive tool, affording identification of mothers with more subtle signs of depression, who do not outwardly appear depressed or suffering from dysfunction, and who would likely have gone unnoticed without use of the screening instrument:

"A certain mother came to the clinic, all smiling, saying 'everything's OK.' When she filled out the questionnaire, it was like opening a Pandora's box. I was amazed; if there's a problem, you just nudge it with the questionnaire, and it all comes out."

In addition, nurses noted that the EPDS provides legitimacy for the distress that mothers may experience postpartum:

"When we use the tool, we legitimize to a mother that the postpartum depression is something that can happen." 
Use of the EPDS offered legitimacy not just for the women attending the clinics. In one instance, a new father who accompanied his wife, asked to fill out the questionnaire also, "What about me?" He asked. He was found to report more signs of depression than did his wife. Thus, the EPDS screening provided legitimacy for the father to ask for help for himself.

The screening program also enabled identification of other problems, such as family abuse. One of the nurses participating reported:

"A certain mother didn't show up at the clinic after delivery, saying she didn't feel well. Three months later we offered her the EPDS and it all came out. It turned out that she was an abused woman. Now she's in a shelter... only with this tool could we have identified her situation. Otherwise, it might have been too late...”

There was a general consensus among the nurses that the use of the EPDS and their intervention activities had contributed to developing their professional skills, and specifically their ability to relate to the emotional aspects of the women in their care, and they noted that it was much easier to deal with emotional issues when they had the opportunity to utilize a structured instrument.

"The use of the questionnaire allows us to be sensitive to the state of the mother... when we use the tool and raise the issue... we relate to her...her functioning, her relationships, her emotions, etc.”

"The structured instrument enables and encourages us to deal with things we dared not to approach before... giving the mother courage to speak. Sometimes mothers wept after filling out the questionnaire."

All of the nurses noted the importance of the availability of contact with the Mental Health Coordinating Nurse for their own support, for providing more immediate response for the mothers when necessary, and for acquiring new information and awareness of PPD.

The nurses' reports indicated that the additional time needed for screening and conversation with the mothers averaged about 20 minutes, including explanation, screening and brief discussion for all women with no signs of depression and additional time spent with some for the intervention.

\section{Discussion}

Due to the prevalence, consequences and severity of PPD, early identification and intervention are vital in the public health sector in Israel, as in other countries. This study examined the feasibility and efficacy of a program in Mother-Child Health Clinics for early and systematic screening and intervention with pregnant and postpartum women reporting symptoms of depression.

Women attending MCHC clinics in five cities participated in this pilot program. In three of the clinics, virtually all of the women approached agreed to participate (refusal rate 1\%-2\%). In a fourth clinic the rate was also relatively low, despite a turnover in staff which may have affected the effectiveness of the program. This high level of acceptability parallels that found in a number of studies across a range of countries, as reported, for example, by Cox and Holden ${ }^{[8]}$ and Gemmill et al. ${ }^{[39]}$. Only in the final clinics (two clinics in one city) did almost half of the women refuse to complete the EPDS. It is suspected that the reason for this high rate was that the population attending these clinics was of strikingly different cultural composition than the general population, in that they were primarily made up of Jewish Ultra-Orthodox women. The particular norms of this group include severe stigmatization of mental illness, to the point where knowledge of such a case could seriously diminish the chances of a woman's family members to receive a marriage proposal from someone from a family with 'healthy' credentials. Further, although the program's planners established contacts with community leaders (i.e. rabbis, educators) to gain 'approval' for women to participate, and complied with their specific requests, there 
was still considerable resistance. On the positive side, despite the social barriers, over half of the women attending these clinics did avail themselves of the screening and intervention offered. This highlights the importance of sensitivity to the particular culture in which such a program is instituted, and finding ways to offer acceptable services for the benefit of the group as a whole. A similar conclusion was arrived at by Zayas et al. ${ }^{[40]}$ in a prenatal/postpartum intervention study, who found that: "While... attentive to cultural sensitivity, we lacked the true collaboration with participants to define common goals and outcomes” (p. 506). Further, despite the evidence for EPDS validity in a broad array of countries and societies, validating appropriate cut-off points for special sub-populations is advisable ${ }^{[8]}$ due, for example, to the reticence among some groups to discuss or admit to emotional difficulties, such as those found among Japanese women in both Japan and England ${ }^{[41]}$.

Although the current study was not intended as epidemiological research, a by-product was the information on rates of depressive symptoms among a random sample of MCHC attendees in these communities. The rate of postpartum depressive symptoms (12.7\%) are within the range expected from the literature ${ }^{[4,5]}$, although lower than the $22.6 \%$ postpartum rate reported by Glasser et al. in an earlier Israeli study ${ }^{[6]}$. In that study, however, there was a sub-group of new immigrants among whom the rate was much higher (35.8\%), while among the Israeli-born subjects the rate was $16.9 \%$. The higher rates during pregnancy have also been reported by others, most recently by Limlomwongse and Liabsuetrakul $^{[42]}$.

Similar results of intervention in primary care settings have been reported by others, with nurses/midwives generally the service providers ${ }^{[29-32,43,44]}$. As Horowitz \& Goodman ${ }^{[3]}$ stated: "Nurses are well positioned to provide guidance about PPD, detect presence of symptoms, and help women obtain mental health evaluation and appropriate treatment” (p. 266).

The findings of the current program indicate that intervention by nurses during pregnancy may contribute to lower PPD rates. Although depression during pregnancy has been found to predict such symptoms postpartum ${ }^{[7,45]}$, the current program found tentative evidence that this risk was moderated among women who were provided with early intervention by community health nurses. A sub-sample of 56 women was screened both during pregnancy and postpartum, with intervention beginning after the pregnancy screen, when indicated. The rate of postpartum depressive symptoms among this group was lower than that of women in the same clinics who were screened postpartum only (i.e., no intervention prior to delivery). Albeit the numbers in this sample are small, but the trend is clear, and supports the unique contribution of early intervention by the MCHC nurse. Comparing studies to generate a consensus has been difficult due to significant variations in methodology and outcome definitions. Even if PPD cannot be precisely predicted during pregnancy, as Austin ${ }^{[46]}$ stresses “. ... the clinical relevance of identifying those women — whether they be 'at risk,' symptomatic, or with a diagnosis of depression or anxiety — who will benefit from monitoring, and where appropriate, early intervention in both the antenatal and postnatal periods” (p. 4). This recommendation to screen during pregnancy as well as postpartum has also recently been confirmed by Mosack \& Shore ${ }^{[47]}$ and Stowe et al. ${ }^{[44]}$. The latter investigated the onset of PPD cases and concluded that depression surveillance was warranted at antenatal visits as well as at postnatal ones, confirming the experience reported by Clark ${ }^{[49]}$ that use of the EPDS during pregnancy facilitates focusing on the emotional needs of the mother, providing both clients and nurses/health-visitors the opportunity to discuss emotional issues, regardless of the EPDS score, and initiate supportive intervention where necessary. An analysis of PPD prevention research from the Cochrane Pregnancy and Childbirth Group trials register ${ }^{[50]}$ noted that "one promising intervention appears to be the provision of intensive postpartum support provided by public health nurses or midwives," and that although prevention programs begun antenatally were not found by them to be more effective than those begun postnatally, identifying mothers 'at-risk' contributed to efforts to prevent PPD. Hopefully, future research will confirm and clarify the nurses' potential for having a positive impact.

The constellation and impact of MCHC nursing as employed in this project may be particular to Israel. The MCHC clinics are located 'in the neighborhood' and include pregnancy and postpartum maternal care, as well as well-baby care (growth and developmental monitoring, inoculations, etc.) until the child is five years old. The nurses often care for a mother 
through several pregnancies, thus the relationship may be long-term, with a sense of trust built between the nurses and the mothers. This association may well strengthen the therapeutic affiliation and enhance the Israeli MCHC nurse's ability to communicate about and provide support for the woman’s emotional needs.

In addition to the apparent advantages for the women, the nurses reported that the program enriched their role and empowered them in their ability to contribute to the well-being of their patients, increasing their job satisfaction, and a majority expressed motivation to continue the program. The participating nurses considered early identification and help for mothers with signs of depression an integral part of their professional function and were pleased to gain the skills and the instrument with which to facilitate this aspect. Gerrard et al. ${ }^{[51]}$ reported similar findings, stating that “...the consensus of opinion from the health visitors was that it had been a positive experience. Most ...planned to continue using the EPDS ... Structured listening visits were viewed by (them) as a positive intervention, and the experience gained by participation in the programme had some very obvious spin-offs.” (p. 1831).

One of the difficulties expressed by the nurses was the resistance of women to being referred to mental health services. This was attributed to both the stigma associated with these services and often to their inaccessibility. Similar findings have been reported by Downie et al. ${ }^{[52]}$. This would indicate that most of the support, and as much professional intervention as possible, would best be conducted in the framework of the MCHC clinic. This, of course, requires that nurses acquire the appropriate tools, and have access to on-site professional support. In this case, the Mental Health Coordinating Nurses were available. As suggested by the current study, this can be achieved efficiently at relatively low cost. While nearly half of the nurses reported feeling that they had adequate knowledge and ability to deal with the issues raised by the program, they did express the need for professional counsel, especially in the case of women who scored high on the EPDS. Davies et al. ${ }^{[30]}$ also reported that health visitors found the availability of the community mental health nurse to be helpful in their project of PPD screening and supportive 'listening visits'. This professional support for the 'front line' nurses, as well as adequate pre-program and ongoing training is a critical part of implementation, since before this is done "one has to ensure that adequate resources are in place to address the psychosocial morbidity that will be detected" ${ }^{[46]}$.

A drawback of the program, as expressed by the nurses, was (not unexpectedly) the need for increased time within the constraints of an already heavy case load and lack of manpower. Although time demands for the program were not recorded systematically, the nurses reported an average of about twenty minutes per client (including those who did and did not require intervention) as the additional time required. This is similar to the average eighteen minutes recorded by nurses in a similar study reported by Akgungor et al. ${ }^{[53]}$.

It was originally thought that conducting the postpartum screen at the visit planned for the infant's inoculation would spare the women coming to the clinic for an extra visit. However, about a third of the nurses considered this timing not optimal, since mothers were often distracted by the infant's restlessness and/or their concern for his distress, and this made conducting the EPDS screen more difficult. This did not afford the atmosphere necessary (on the part of both the mother and the nurse) for focusing attention on the mother herself. Thus, several of the nurses suggested that in the future the two visits not be combined if possible.

Society as a whole, and the health system in particular, have an interest in ameliorating the burden of PPD. Mothers shape the generations of the future and, in turn, the future of society. While the impact in social and personal terms and quality of life is difficult to quantify, there is a clearer price in economic terms ${ }^{[54]}$.

In light of the success of this program for identifying mothers with signs of pregnancy and postpartum depression, and the receptiveness of nurses and the women in their care, the program was expanded by the Ministry of Health to other areas of the country, at the pace at which nurse training and support can be provided. Expressing its commitment to providing maternal care services in a holistic manner, the Public Health Service of the Ministry has recently issued a directive making antenatal and postpartum EPDS screening by nurses in all MCHC clinics mandatory as of January 1, 2013. 
Indeed, although such programs may be considered innovative, they may actually be, as stated by Boyce et al. ${ }^{[55]}$ : “... really no more than good clinical care, the type of care that has become lost in the way medicine has evolved. It is nothing new, merely a return to the way medicine used to be”. Community nurses have a unique and important part to play in this revival for the betterment of the women in their care.

\section{Acknowledgements}

The authors express their appreciation to Ms. Vita Barell, of blessed memory, who as the Head of the Unit for Health Services Research, Gertner Institute, was instrumental in guiding and supporting this program. We thank Ms. Yael Shachar for her competent and efficient assistance in preparation of this manuscript. We also sincerely thank the nurses who participated in this program, whose cooperation and dedication made fruition possible.

\section{References}

[1] Scrandis DA, Sheikh TM, Niazi R, Tonelli LH, Postolache TT. Depression after delivery: risk factors, diagnostic and therapeutic considerations. Scientific World Journal. 2007; 22(7): 1670-82. PMid:17982562 http://dx.doi.org/10.1100/tsw.2007.207

[2] Gale S, Harlow L. Postpartum mood disorders: A review of clinical and epidemiological factors. Journal of Psychosomatic Obstetrics \& Gynecology. 2003; 24: 257-266. http://dx.doi.org/10.3109/01674820309074690

[3] Horowitz JA, Goodman JH. Identifying and treating postpartum depression. Journal of Obstetric Gynecologic \& Neonatal Nursing. 2005; 34: 264-273. PMid:15781605 http://dx.doi.org/10.1177/0884217505274583

[4] Gaynes BN, Gavin N, Meltzer-Brody S, Lohr KN, Swinson T, Gartlehner G, et al. Perinatal depression: prevalence, screening accuracy, and screening outcomes. Evidence Report/Technology Assessment. 2005; 119: 1-8.

[5] O'hara MW, Swain AM. Rates and risk of postpartum depression—a meta-analysis. International Review of Psychiatry. 1996; 8: 37-54. http://dx.doi.org/10.3109/09540269609037816

[6] Glasser S, Barell V, Shoham A, Ziv A, Boyko V, Lusky A, et al. Prospective Study of postpartum depression in an Israeli Cohort: Prevalence, incidence and demographic risk factors. Journal of Psychosomatic Obstetrics and Gynecology. 1998; 19: 155-164. PMid:9844846 http://dx.doi.org/10.3109/01674829809025693

[7] Glasser S, Barell V, Boyko V, Ziv A, Lusky A, Shoham A, et al. Postpartum depression in an Israeli cohort: Demographic, psychosocial and medical risk factors. Journal of Psychosomatic Obstetrics and Gynecology. 2000; 21: 99-108. PMid:10994182 http://dx.doi.org/10.3109/01674820009075615

[8] Cox JL, Holden J. A Guide to the Edinburgh Postnatal Depression Scale. January 2003. London: Gaskell.

[9] Klainin P, Arthur AG. Postpartum depression in Asian cultures: a literature review. International journal of nursing studies. 2009; 46(10): 1355-1373. PMid:19327773 http://dx.doi.org/10.1016/j.ijnurstu.2009.02.012

[10] Leung SSK, Martinson IM, Arthur D. Postpartum depression and related psychosocial variables in Hong Kong Chinese women: Findings from a prospective study. Research in Nursing \& Health. 2005; 28: 27-38. PMid:15625707 http://dx.doi.org/10.1002/nur.20053

[11] Rubertsson C, Wickberg B, Gustavsson P, Radestad I. Depressive symptoms in early pregnancy, two months and one year postpartum-prevalence and psychosocial risk factors in a national Swedish sample. Archives of Women's Mental Health. 2005; 8: 97-104. PMid:15883652 http://dx.doi.org/10.1007/s00737-005-0078-8

[12] Ghubash R, Eapen V. Postpartum Mental Illness: Perspectives From An Arabian Gulf Population. Psychological Reports. 2009; 105: 127-136. http://dx.doi.org/10.2466/pr0.105.1.127-136

[13] Brockington I. Postpartum psychiatric disorders. The Lancet. 2004; 363: 303-310. http://dx.doi.org/10.1016/S0140-6736(03)15390-1

[14] O'Hara MW. Postpartum depression: what we know? Journal of clinical psychology. 2009; 65(12): 1258. PMid:19827112 http://dx.doi.org/10.1002/jclp.20644

[15] Edhborg M, Friberg M, Lundh W, Widstrom AM. ”Struggling with life”: Narratives from women with signs of postpartum depression. Sandinavian Journal of Public Health. 2005; 33: 261-267. PMid:16087488 http://dx.doi.org/10.1080/14034940510005725

[16] Goodman JH. Postpartum depression beyond the early postpartum period. Journal of Obstetric Gynecologic \& Neonatal Nursing. 2004a; 33: 410-420. PMid:15346666 http://dx.doi.org/10.1177/0884217504266915

[17] Murray L, Cooper P, Hipwell A. Mental health of parents caring for infants. Archive Women's Mental Health. 2003; 6: Suppl. 2, S71-S77. PMid:14615925 http://dx.doi.org/10.1007/s00737-003-0007-7 
[18] Leigh B, Milgrom J. Risk factors for antenatal depression, postnatal depression and parenting stress. BMC Psychiatry. 2008; 8: 24-34. PMid:18412979 http://dx.doi.org/10.1186/1471-244X-8-24

[19] Diego MA, Field T, Hernandez-Reif M, Cullen C, Schanberg S, Kuhn C. Prepartum, postpartum, and chronic depression effects on newborns. Psychiatry. 2004; 67: 63-80. PMid:15139586 http://dx.doi.org/10.1521/psyc.67.1.63.31251

[20] Hay DF, Pawlby S., Angold A, Harold HT, Sharp D. Pathways to violence in the children of mothers who were depressed postpartum. Developmental Psychology. 2003; 39: 1083-1094. PMid:14584986 http://dx.doi.org/10.1037/0012-1649.39.6.1083

[21] Hay DF, Pawlby S, Sharp D, Asten P, Mills A, Kumar R. Intellectual problems shown by 11-year-old children whose mothers had postnatal depression. Journal of Child Psychology andPsychiatry. 2001; 42: 871-889. http://dx.doi.org/10.1111/1469-7610.00784

[22] Murray L, Cooper P, Hipwell A. Mental health of parents caring for infants. Archive Women's Mental Health. 2003; 6: Suppl. 2, S71-S77. PMid:14615925 http://dx.doi.org/10.1007/s00737-003-0007-7

[23] Murray L, Sinclair D, Cooper P, Ducournau P, Turner P, Stein A. The socioemotional development of 5-year-old children of postnatally depressed mothers. Journal of Child Psychology Psychiatry. 1999; 40: 1259-1271. http://dx.doi.org/10.1111/1469-7610.00542

[24] Goodman JH. Paternal postpartum depression, its relationship to maternal depression and implications for family health. Journal of Advanced Nursing. 2004b; 45: 26-35. PMid:14675298 http://dx.doi.org/10.1046/j.1365-2648.2003.02857.x

[25] Hackney, M. The effect of postnatal depression on older siblings. Marce' Society Bulletin. 1996; March: 12-13.

[26] Johanson R, Chapman G, Murray D, Johnson I, Cox J. The North Staffordshire Maternity Hospital prospective study of pregnancyassociated depression. Journal of Psychosomatic Obstetrics and Gynaecology. 2000; 21: 93-97. PMid:10994181 http://dx.doi.org/10.3109/01674820009075614

[27] Bagedahl-Strindlund M, Monsen BK. Postnatal depression: a hidden illness. Acta Psychiatrica Scandinavica. 1998; 98: $272-275$. http://dx.doi.org/10.1111/j.1600-0447.1998.tb10083.x

[28] Wisner KL, Scholle SH, Stein B. Perinatal disorders: advancing public health opportunities. Journal of Clinical Psychiatry. 2008; 69(10): 1602-1605. PMid:19192443 http://dx.doi.org/10.4088/JCP.v69n1010

[29] Tezel A, Gozum S. Comparison of effects of nursing care to problem solving training on levels of depressive symptoms in post partum women. Patient Education and Counseling. 2006; 63: 64-73. PMid:16448799 http://dx.doi.org/10.1016/j.pec.2005.08.011

[30] Davies BR, Howells S, Jenkins M. Early detection and treatment of postnatal depression in primary care. Journal of Advanced Nursing. 2003; 44: 248-255. PMid:14641394 http://dx.doi.org/10.1046/j.1365-2648.2003.02799.x

[31] MacArthur C, Winter HR, Bick DE, Lilford RJ, Lancashire RJ, Knowles H et al. Redesigning postnatal care: a randomized trial of protocol-based midwifery-led care focused on individual women's physical and psychological health needs. Health Technology Assessment. 2003; 7: 1-98. PMid:14622490

[32] Palti H, Gofin R, Adler B. Evaluation of utilization of preventive services for infants in Israel—personal and organizational determinants. Harefuah. 2004; 143: 184-188, 247. PMid:15065355

[33] Cox JL, Holden JM, Sagovsky R. Detection of postnatal depression: Development of the 10-item Edinburgh Postnatal Depression Scale. British Journal of Psychiatry. 1987; 150: 782-786. PMid:3651732 http://dx.doi.org/10.1192/bjp.150.6.782

[34] Glasser S, Barell V. Depression scale for research and identification of postpartum depression. Harefua, 1999; 136: $764-768$.

[35] Kandel-Katznelson S, Maisel S, Zilber N, Lerner J. Validation of the Hebrew translation of the Edinburgh Postnatal Depression Scale: background, methods and findings. Tenth Annual Conference of the Israeli Psychiatric Association; Jerusalem, April, 2000. (in Hebrew).

[36] Murray L, Carothers AD. The validation of the Edinburgh Post-natal Depression Scale on a community sample. British Journal of Psychiatry. 1990; 157: 288-290. http://dx.doi.org/10.1192/bjp.157.2.288

[37] Navarro P, García-Esteve L, Ascaso C, Aguado J, Gelabert E, Martín-Santos R. Non-psychotic psychiatric disorders after childbirth: prevalence and comorbidity in a community sample. Journal of Affective Disorders. 2008; 109(1-2): 171-176. PMid:18001842 http://dx.doi.org/10.1016/j.jad.2007.10.008

[38] Matthey S, Henshaw C, Elliot S, Barnett B. Variability in use of cut-off scores and formats on the Edinburgh Postnatal Depression Scale-implications for clinical and research practice. Archives of Women’s Mental Health. 2006; 9: 309-315. PMid:17013761 http://dx.doi.org/10.1007/s00737-006-0152-x

[39] Gemmill AW, Leigh B, Ericksen J, Milgrom J. A Survey of the clinical acceptability of screening for postnatal depression in depressed and non-depressed women. BMC Public Health (online resource). 2006; 17: 6, 211.

[40] Zayas LH, McKee MD, Jankowski KR. Adapting psychosocial intervention research to urban primary care environments: A case example. Annual Family Medicine. 2004; 2: 504-508. http://dx.doi.org/10.1370/afm.108

[41] Yoshida K, Markd MN, Kibe N, Kumar R, Nakano H, Tashiro N. Postnatal depression in Japanese women who have given birth in England. Journal of Affective Disorders. 1997; 43: 69-77. http://dx.doi.org/10.1016/S0165-0327(96)01419-X 
[42] Limlomwongse, N, Liabsuetrakul T. Cohort study of depressive moods in Thai women during late pregnancy and 6-8 weeks of postpartum using the Edinburgh Postnatal Depression Scale. Archives of Women's Mental Health. 2006; 9: 131-138. PMid:16329000 http://dx.doi.org/10.1007/s00737-005-0115-7

[43] Osborn T. Training health visiting support staff to detect likelihood of possible postnatal depression. Community Practitioner. 2012; 85(4): 24-27. PMid:22586865

[44] Morrell CJ, Ricketts T, Tudor K, Williams C, Curran J, Barkham M. Training health visitors in cognitive behavioural and personcentred approaches for depression in postnatal women as part of a cluster randomised trial and economic evaluation in primary care: the PoNDER trial. Primary Health Care Research \& Development. 2011; 12(1): 11-20. PMid:21426611 http://dx.doi.org/10.1017/S1463423610000344

[45] Robertson E, Grace S, Wallington T, Evaluation of utilization of preventive services for infants in Israel Stewart D.E. Antenatal risk factors for postpartum depression: A synthesis of recent literature. General Hospital Psychiatry. 2004; 26: $289-295$. PMid:15234824 http://dx.doi.org/10.1016/j.genhosppsych.2004.02.006

[46] Austin MP. Antenatal screening and early intervention for "perinatal" distress, depression and anxiety: where to form here? Archives of Women's Mental Health. 2004; 7: 1-6. PMid:14963727 http://dx.doi.org/10.1007/s00737-003-0034-4

[47] Mosack V, Shore ER. Screening for depression among pregnant and postpartum women. Journal of Community Health Nursing. 2006; 23: 37-47. PMid:16445363 http://dx.doi.org/10.1207/s15327655jchn2301_4

[48] Stowe ZN, Hostetter AL, Newport DJ. The onset of postpartum depression: implications for clinical screening in obstetrical and primary care. American Journal of Obstetrics and Gynecology. 2005; 192: 522-526. PMid:15695997 http://dx.doi.org/10.1016/j.ajog.2004.07.054

[49] Clark G. Discussing emotional health in pregnancy: The Edinburgh Postnatal Depression Scale. British Journal of Community Nursing. 2000; 5: 91-98. PMid:11125459

[50] Dennis CL, Creedy D. Psychosocial and psychological interventions for preventing postpartum depression (Review). The Cochrane Database. 2004; 4: 1-10.

[51] Gerrard J, Holden JM, Elliott SA, McKenzie P, McKenzie J, Gemmill AW, Leigh B, Cox JL. A trainer's perspective of an innovative programme teaching health visitors about the detection, treatment and prevention of postnatal depression. Journal of Advanced Nursing. 1993; 18: 1825-1832. http://dx.doi.org/10.1046/j.1365-2648.1993.18111825.x

[52] Downie J, Wynaden D, McGowan S, Juliff D, Axten C, Fitzpatrick L, Ogilvie S, Painter S. Using the Edinburgh postnatal depression scale to achieve best practice standards. Nursing \& Health Sciences. 2003; 5: 283-287. http://dx.doi.org/10.1046/j.1442-2018.2003.00164.x

[53] Akgungor A, Harlan C, Kimak C, Leonard D, Lang S, Rowe-Kaminsky J. Screening for postpartum depression within a community health setting: Costs and Benefits. Edmonton, Alberta: Capital Health, 1997.

[54] Lynch T, Harrington J. Benefit-cost analysis of the Maternal Depression Project in Gadsden County, Florida. Talahassee, Fla.: Center for Economic Foercasting and Analysis, 2003.

[55] Boyce P, Starick D, Hickey A, Price J. A brief intervention to lower the risk for postnatal depression: a step forward or turning the clock back? Marce Society Bulletin, 1996; 14-19. 